\title{
Safety profile of COVID-19 drugs in a real clinical setting
}

\author{
Mei Nee Chiu ${ }^{1} \cdot$ Maitry Bhardwaj ${ }^{1}$ Sangeeta Pilkhwal Sah ${ }^{1,2}$ (i) \\ Received: 10 August 2021 / Accepted: 18 December 2021 / Published online: 28 January 2022 \\ (c) The Author(s), under exclusive licence to Springer-Verlag GmbH Germany, part of Springer Nature 2021
}

\begin{abstract}
Purpose The coronavirus disease 2019 (COVID-19) caused by the severe acute respiratory syndrome coronavirus 2 (SARSCoV-2) virus has affected millions all over the world and has been declared pandemic, as of 11 March 2020. In addition to the ongoing research and development of vaccines, there is still a dire need for safe and effective drugs for the control and treatment against the SARS-CoV-2 virus infection. Numerous repurposed drugs are under clinical investigations whose reported adverse events can raise worries about their safety. The aim of this review is to illuminate the associated adverse events related to the drugs used in a real COVID-19 setting along with their relevant mechanism(s).

Method Through a literature search conducted on PubMed and Google Scholar database, various adverse events suspected to be induced by eight drugs, including dexamethasone, hydroxychloroquine, chloroquine, remdesivir, favipiravir, lopinavir/ ritonavir, ivermectin, and tocilizumab, administered in COVID-19 patients in clinical practice and studies were identified in 30 case reports, 3 case series, and 10 randomized clinical trials.

Results Mild, moderate, or severe adverse events of numerous repurposed and investigational drugs caused by various factors and mechanisms were observed. Gastrointestinal side effects such as nausea, abdominal cramps, diarrhea, and vomiting were the most frequently followed by cardiovascular, cutaneous, and hepatic adverse events. Few other rare adverse drug reactions were also observed.

Conclusion In light of their ineffectiveness against COVID-19 as evident in large clinical studies, drugs including hydroxychloroquine, lopinavir/ritonavir, and ivermectin should neither be used routinely nor in clinical studies. While lack of sufficient data, it creates doubt regarding the reliability of chloroquine and favipiravir use in COVID-19 patients. Hence, these two drugs can only be used in clinical studies. In contrast, ample well-conducted studies have approved the use of remdesivir, tocilizumab, and dexamethasone under certain conditions in COVID-19 patients. Consequently, it is significant to establish a strong surveillance system in order to monitor the proper safety and toxicity profile of the potential anti-COVID-19 drugs with good clinical outcomes.
\end{abstract}

Keywords Adverse events $\cdot$ Pharmacovigilance $\cdot$ COVID-19 $\cdot$ Adverse drug reactions

\section{Introduction}

The world is experiencing one of its most turbulent times with the outbreak of the coronavirus disease 2019 (COVID19) pandemic. First identified in Wuhan city of Hubei Province, China, in December 2019, the deadly virus has spread

Sangeeta Pilkhwal Sah

spilkhwal@ rediffmail.com

1 University Institute of Pharmaceutical Sciences (UIPS), Panjab University, Chandigarh 160014, India

2 University Institute of Pharmaceutical Sciences UGC Centre of Advanced Study (UGC-CAS), Panjab University, Chandigarh 160014, India across the countries and affected countless [1]. According to World Health Organization (WHO), as of 14 June 2021, there have been $75,541,600$ cases of severe acute respiratory syndrome coronavirus 2 (SARS-CoV-2) infected patients confirmed so far, of which there are 3,798,361 deaths, globally. On 9 June 2021, WHO declared that a total of $2,156,550,767$ vaccine doses have been administered [2]. Therefore, although society and researchers at large have successfully worked towards the development of several vaccines, there still exists a need to discover safe and effective, potential drug candidates for the treatment of COVID-19, especially for patients exhibiting critical clinical symptoms. One efficient and economic approach to identifying promising therapeutic drugs is drug repurposing, which refers 
to the repositioning or reprofiling of existing medications against viruses, malaria, cancer, and arthritis for a new indication, in this case for COVID-19 [3]. A convenient method utilizing already available drugs with known mechanism, pharmacokinetic and pharmacodynamic characteristics, efficacy, and toxicity profiles leads to low cost and less time consumption for drug development [3, 4]. However, in urgency for early and immediate effective treatments, less consideration has been given to their safety in terms of its associated adverse events. Though the significant investigation of adverse events is lacking, reports from existing studies suggest gastrointestinal, cardiovascular, dermatologi$\mathrm{cal}$, and liver symptoms to be some of the common adverse drug reactions among many others in patients after receiving antiviral therapy for COVID-19 [5]. Causality assessment to determine the exact cause of effects is a big challenge owing to the interweaving contributing, confounding risk factors, and incomplete data or background of the event [6]. Thus, strengthened surveillance of therapeutics and its potentially harmful adverse effects or pharmacovigilance is the need of the hour for better management of COVID-19 therapies.

Considering the inadequate literature on patient safety outcomes for COVID-19 medications, this review aims to elucidate the recent adverse drug events associated with eight potential drugs used against SARS-CoV-2 infection in COVID-19 patients.

\section{Search strategy}

A literature search, up to June 2021, was conducted on PubMed and Google Scholar database for studies on AEs suspected to be induced by drugs used against COVID-19. The following keywords (alone or in combination) were used: "adverse drug reactions," "adverse effects," "COVID-19 drugs," "dexamethasone," "remdesivir," "favipiravir," "hydroxychloroquine," "chloroquine," "lopinavir/ritonavir," "tocilizumab," "ivermectin," and "side effect." Only studies where patients with COVID-19 illness were included. Case reports, case series, and randomized clinical trials published in the English language were taken into account.

\section{Repurposed drugs which have been evaluated as potential treatment options against SARS-CoV-2}

The transmission of the SARS-CoV-2 virus via respiratory droplets or aerosols from one person to another takes place while coughing, talking, and sneezing [7]. After transmission, the replication cycle of the SARS-CoV-2 virus inside the host cell can be divided into the following major steps: binding and entry into a host cell, viral replicase transcription, genomic transcription and replication, translation of structural proteins, and assembly and release of the virus.

Repurposing different drug agents targeting these key stages of the SARS-CoV-2 virus life cycle could be an effective and faster approach towards antiviral drug development [8]. Figure 1 depicts the infection life cycle of the SARS-COV-2 virus and effective targets of potential therapeutic drug candidates interfering with the steps of viral replication.

Though repurposing of drugs has hastened the drug development process in the most economical approach, however, in the efforts of searching for a potential therapeutic drug, the exact safety and toxicity profiles of drug candidates have been overlooked. Various sources point to the association of several adverse events with different therapeutic agents currently being used or under clinical trials. Some pieces of evidence demonstrate gastrointestinal side effects such as nausea, vomiting, diarrhea, abdominal pain, cardiovascular adverse events like QT interval prolongation, cardiac arrhythmia, dermatological adverse events including skin rash, Stevens-Johnson syndrome, maculopapular eruptions, alopecia, erythema, pruritus, and hyperpigmentation, liver injury, and many other uncommon adverse drug reactions of several repurposed and investigational drugs $[9,10]$. Table 1 summarizes the findings on the various AEs caused by COVID-19 medications in patients infected with the SAR-CoV-2 virus, as reported by case reports, case series, and randomized clinical trials.

The following sections will illuminate the eight most common anti-COVID-19 drugs, their mechanism of action, and their related adverse events, as found in the published literature.

\section{Dexamethasone}

Anti-inflammatory agents like glucocorticoids, such as dexamethasone, have been widely used in the treatment of diseases closely related to SARS-CoV-2 infection, such as SARS, MERS, and influenza. However, earlier, the evidence to support or discourage its use for COVID-19 was lacking.

In a large, open-label randomized controlled RECOVERY trial, 2104 hospitalized patients with COVID-19 were administered either orally or intravenously with $6 \mathrm{mg}$ of dexamethasone once a day for 10 days. The trial provided evidence of reduced 28-day mortality in patients on respiratory support. However, the clinical outcomes related to dexamethasone also included four cases of serious adverse reactions, namely, two reports of hyperglycemia, and one of gastrointestinal hemorrhage, and psychosis each [11]. 


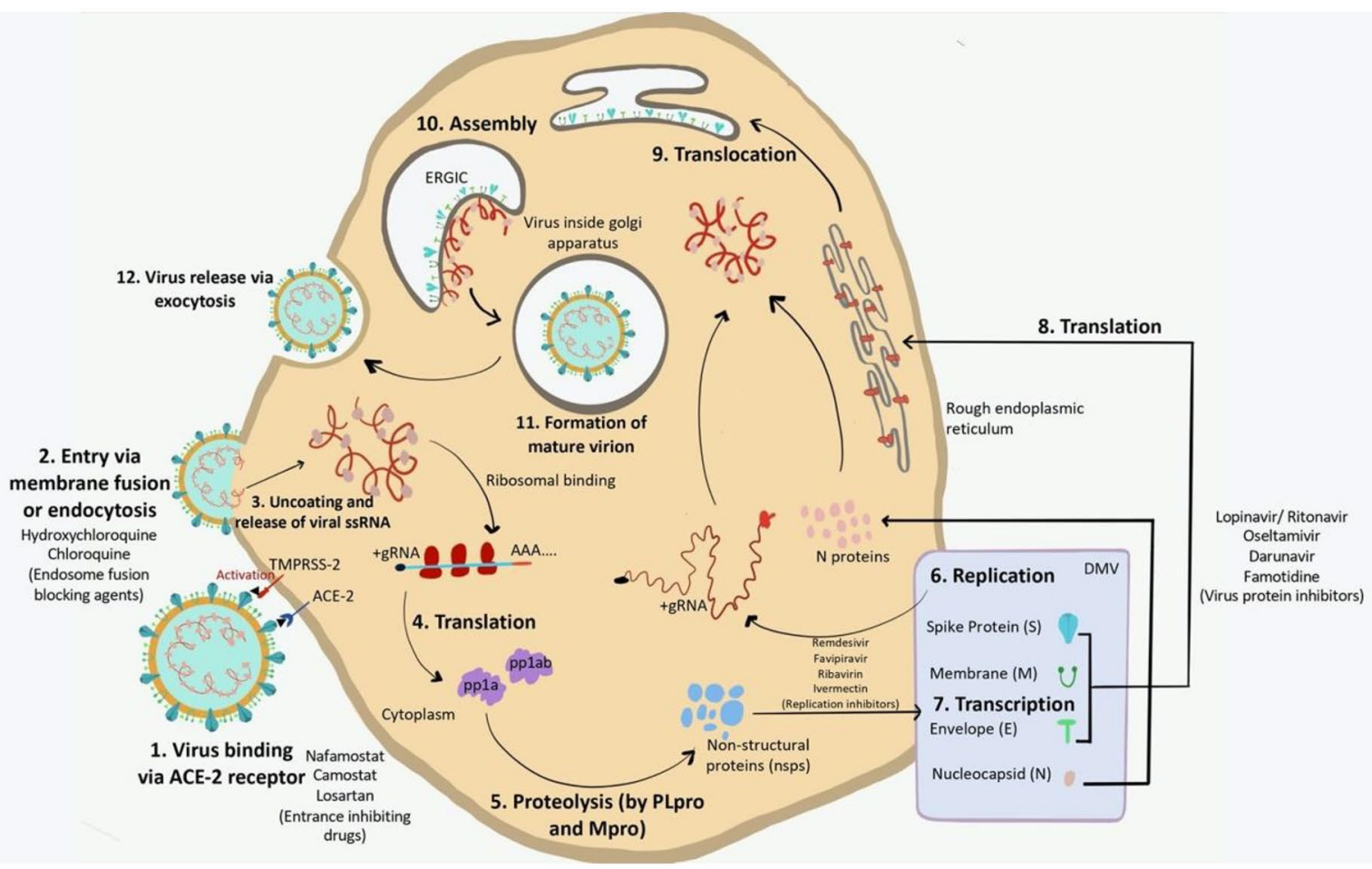

Fig. 1 Step by step (1-12) life cycle of SARS-COV-2 virus infection from the attachment of the virus to ACE-2 receptor of the host cell to release of newly formed virus particles and the various target sites of potential therapeutic drug candidates

\section{Hydroxychloroquine}

Widely used antimalarials, hydroxychloroquine, and chloroquine with well-established use in autoimmune disorders like rheumatoid arthritis and lupus erythematosus have been repurposed for their potential antiviral activity against SARS-CoV-2 infection [54, 55]. Though large trials conducted in the past year have already revealed the ineffectiveness of hydroxychloroquine in the treatment of COVID-19 and lack of adequate positive data in case of chloroquine has allowed its use for clinical research only.

Belonging to the 4-aminoquinoline class of compounds, both exert anti-inflammatory, immunomodulatory, and antiviral action through a wide array of specific mechanisms [56]. This includes the rise in the endosome and lysosomal $\mathrm{pH}$, interference in endocytic activity, obstruction of sialic acid receptors, blocking of SARS-CoV-2 entry into the host cell by prevention of glycosylation of ACE2 receptors, and control of cytokine storm induced by inflammatory mediators [57], thus inhibiting the entry, replication, and release of the virus from the host organism. Hydroxychloroquine, in addition to possessing better potency against SARS-CoV-2, causes less toxicity as compared to chloroquine [58, 59]. Nonetheless, its administration for treatment of coronavirus disease 2019 is not one without adverse events.
In their article, Zengin et al. [12] presented three case reports indicating the association of hydroxychloroquine therapy with cardiovascular adverse effects. Primarily, its potential to cause serious QT interval prolongation and cardiac arrhythmias. The mechanism suggested to induce such effects was the inhibitory action on the hyperpolarized cardiac channels that resulted in the delay of depolarization rate and eventually decreased heart rate [13]. As shown in several case reports and case series, coadministration of HCQ with QT prolonging medications like azithromycin may increase the risk of cardiac toxicity among many other factors including age, sex, duration of therapy, hepatic or renal failure, and pre-existing cardiovascular disease $[13,20]$. In a case report by Asli et al., patient was administrated with lopinavir/ritonavir, another QTc prolonging agent concomitantly with HCQ that might have contributed to the cause of right bundle branch block (RBBB) and severe QTc interval prolongation [19]. Another such case of an 84-year-old woman with history of hypertension, Alzheimer's disease, and stage 4 chronic kidney disease (CKD) suggested the close relation of HCQ with sinus bradycardia and QTc prolongation. The QTc levels normalized after discontinuation of drug along with intravenous administration of isoproterenol and epinephrine [15]. In most of the studies, patient QTc intervals and symptoms improved soon after discontinuation of the 


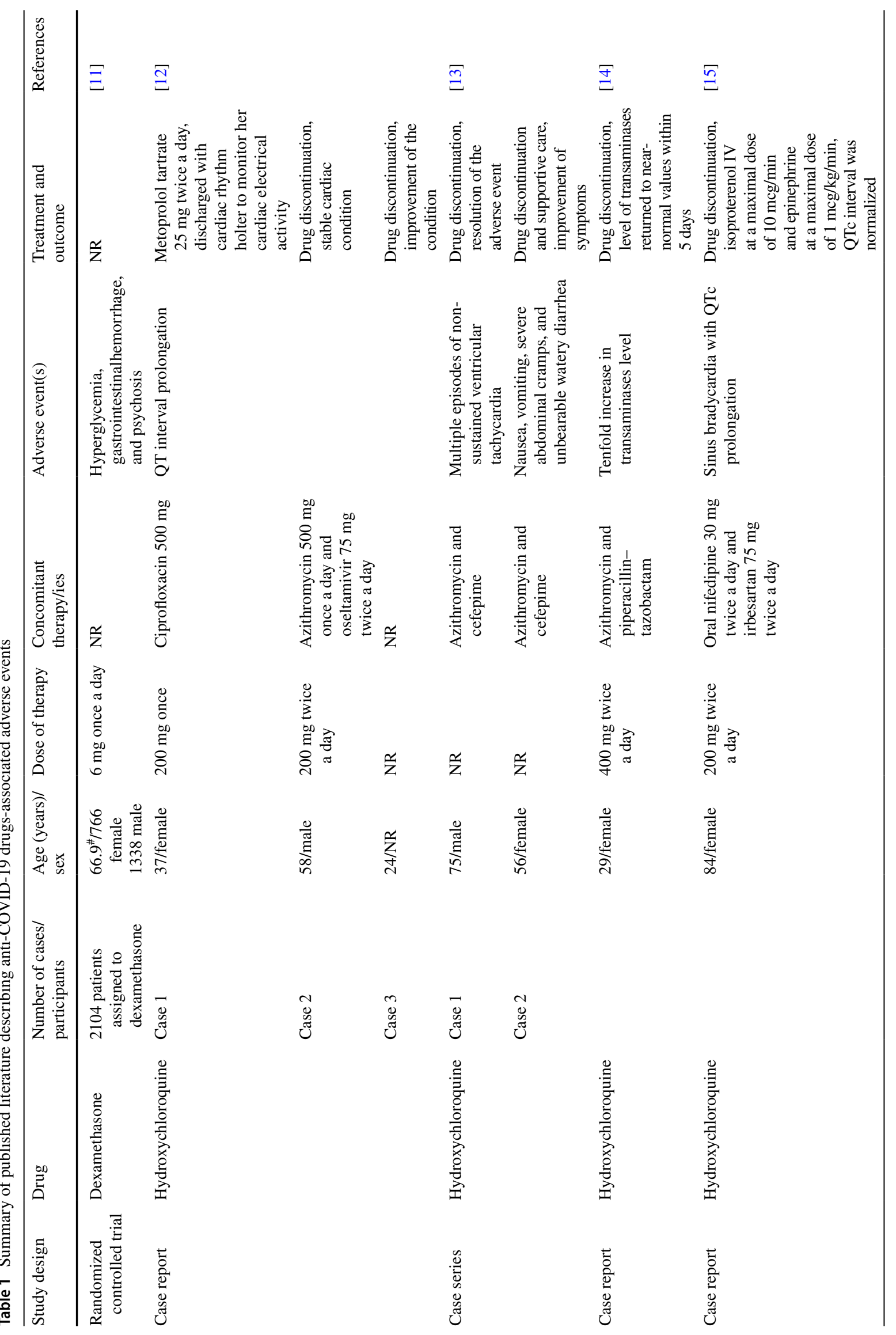




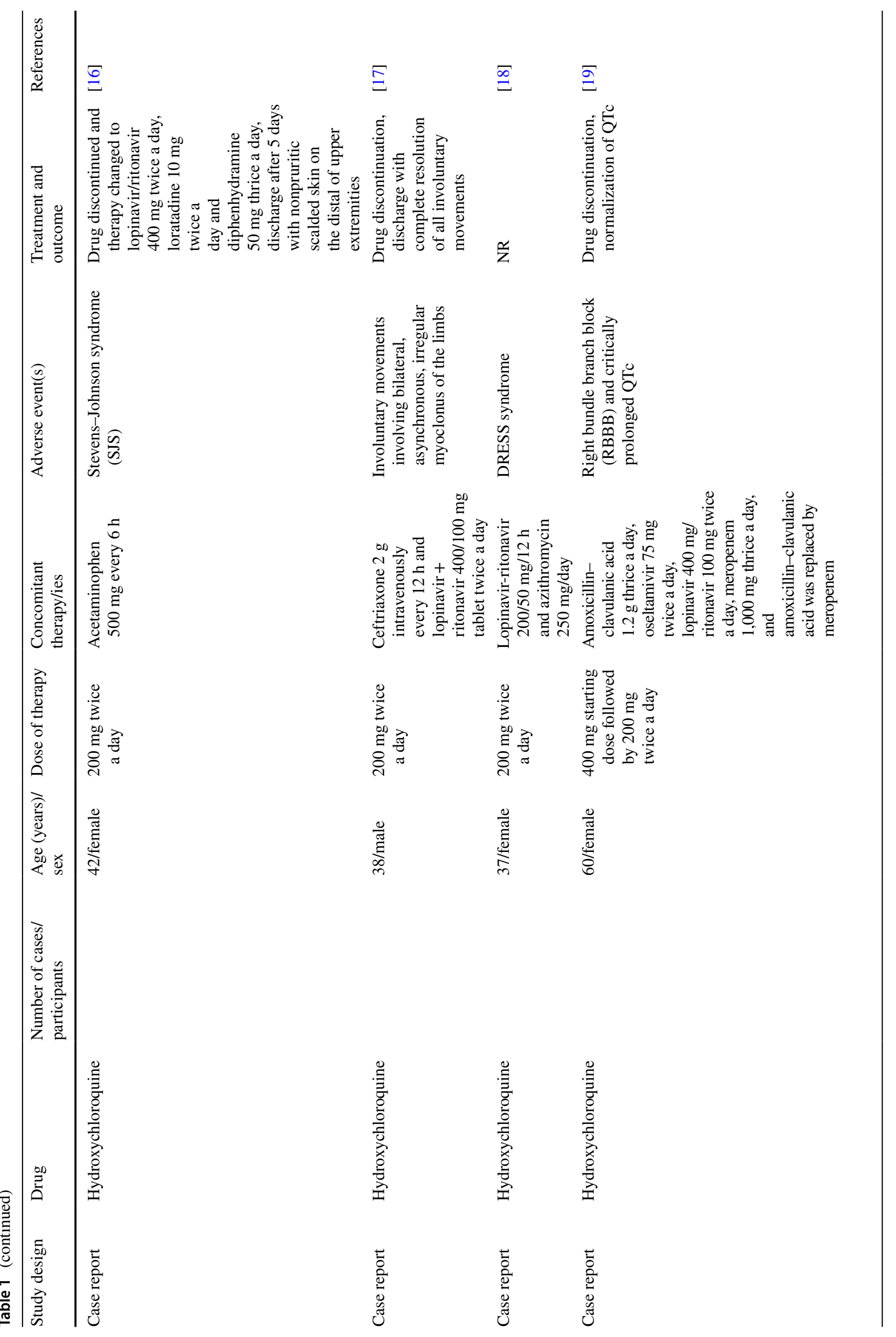




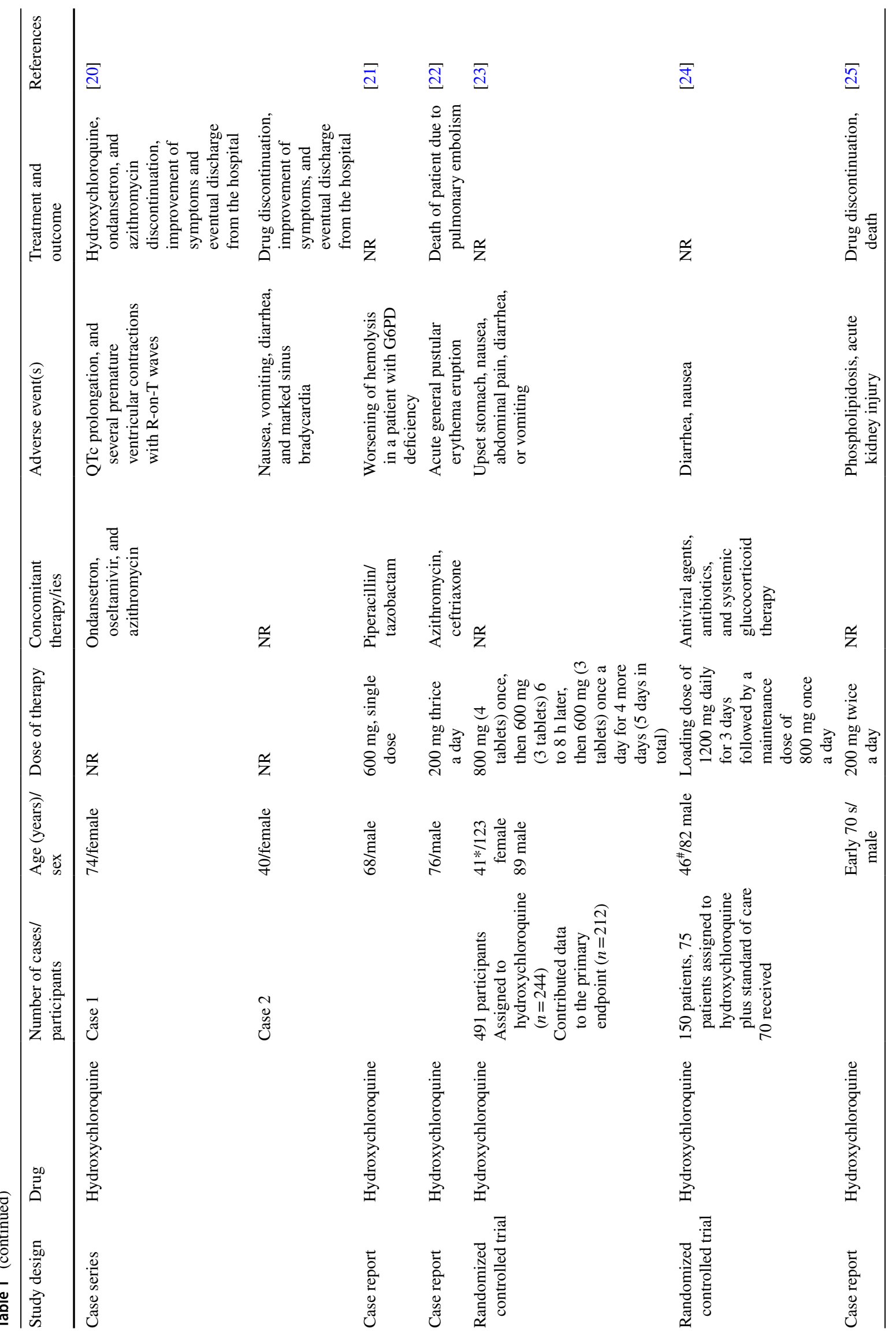




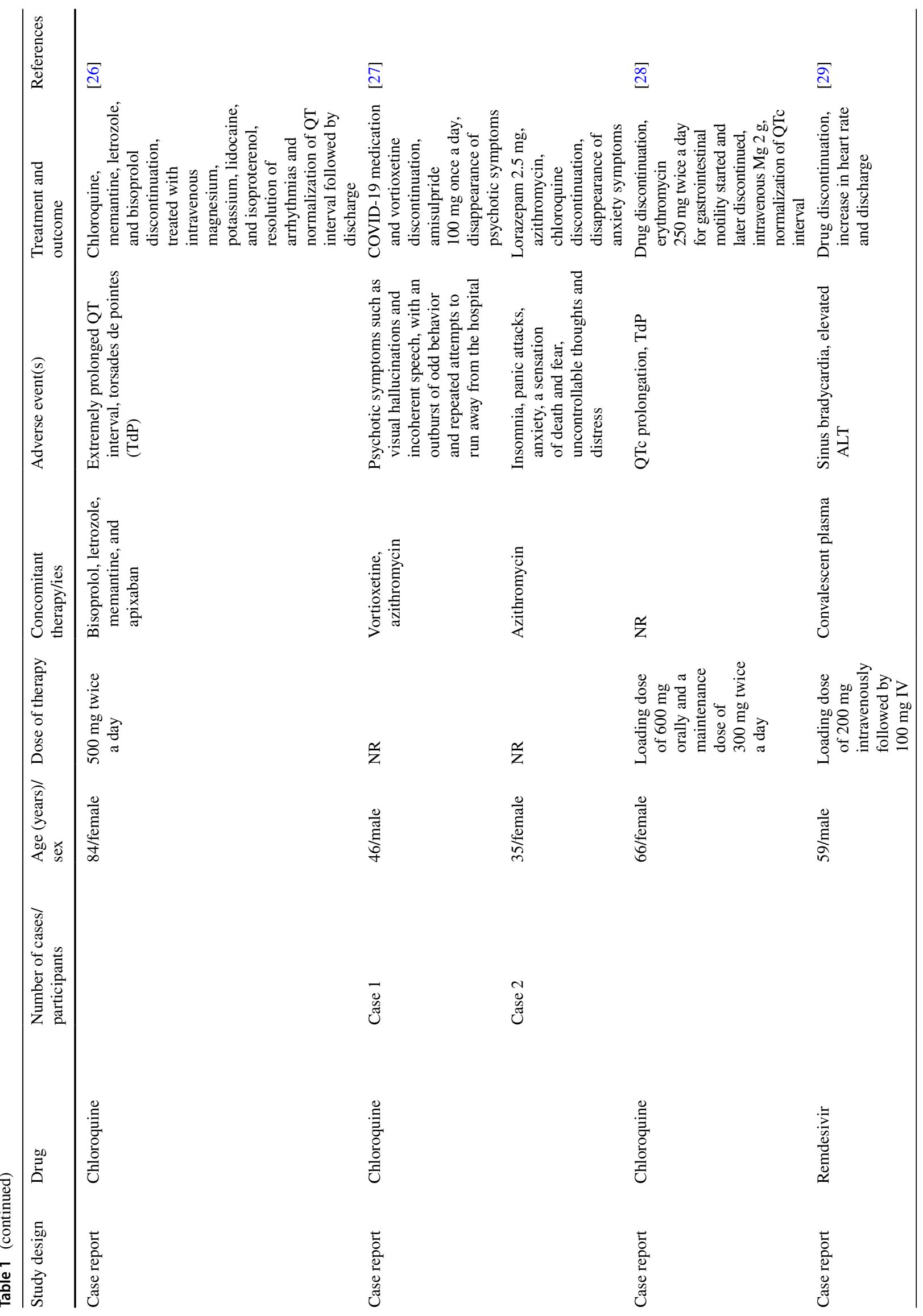




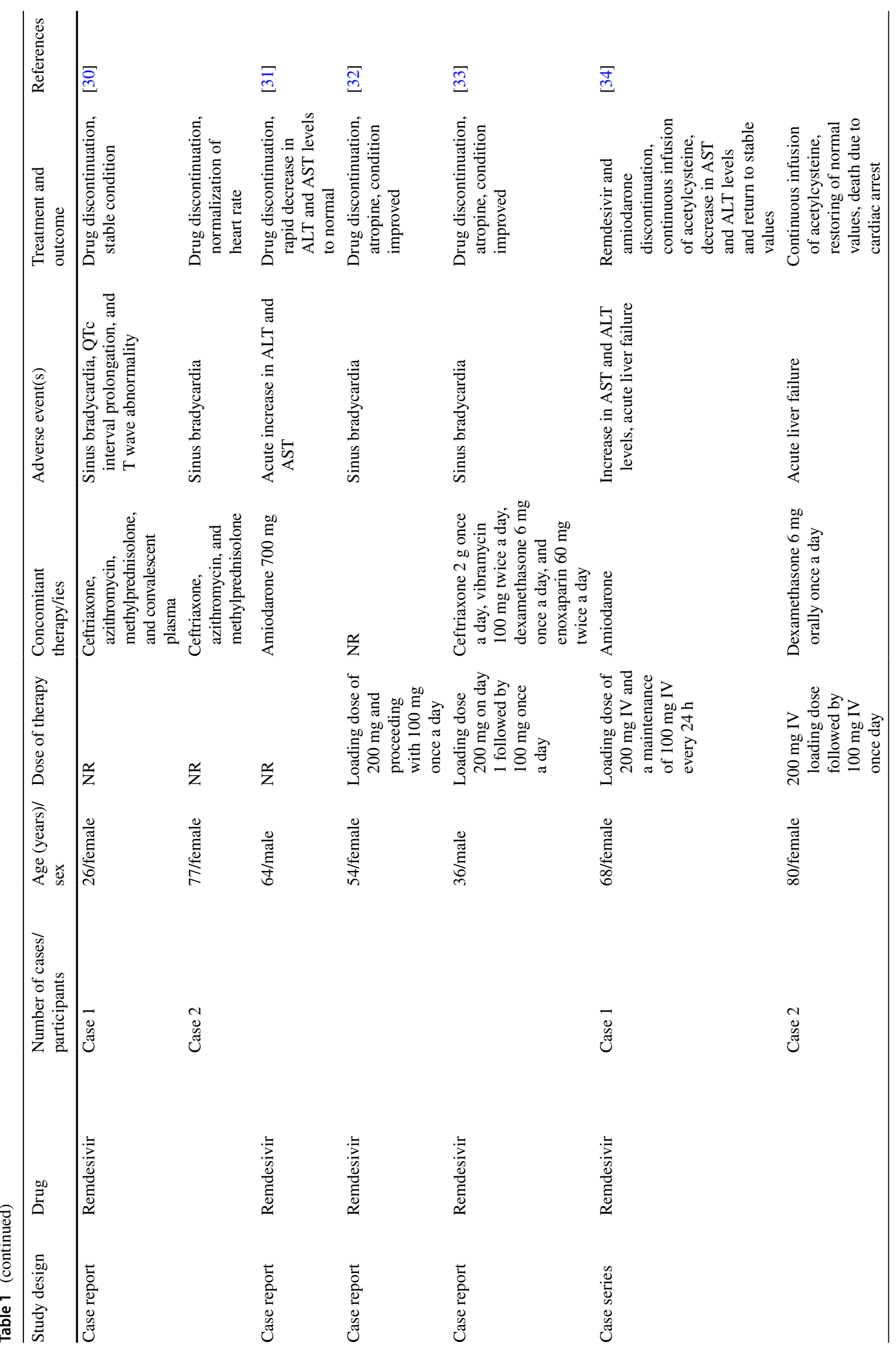




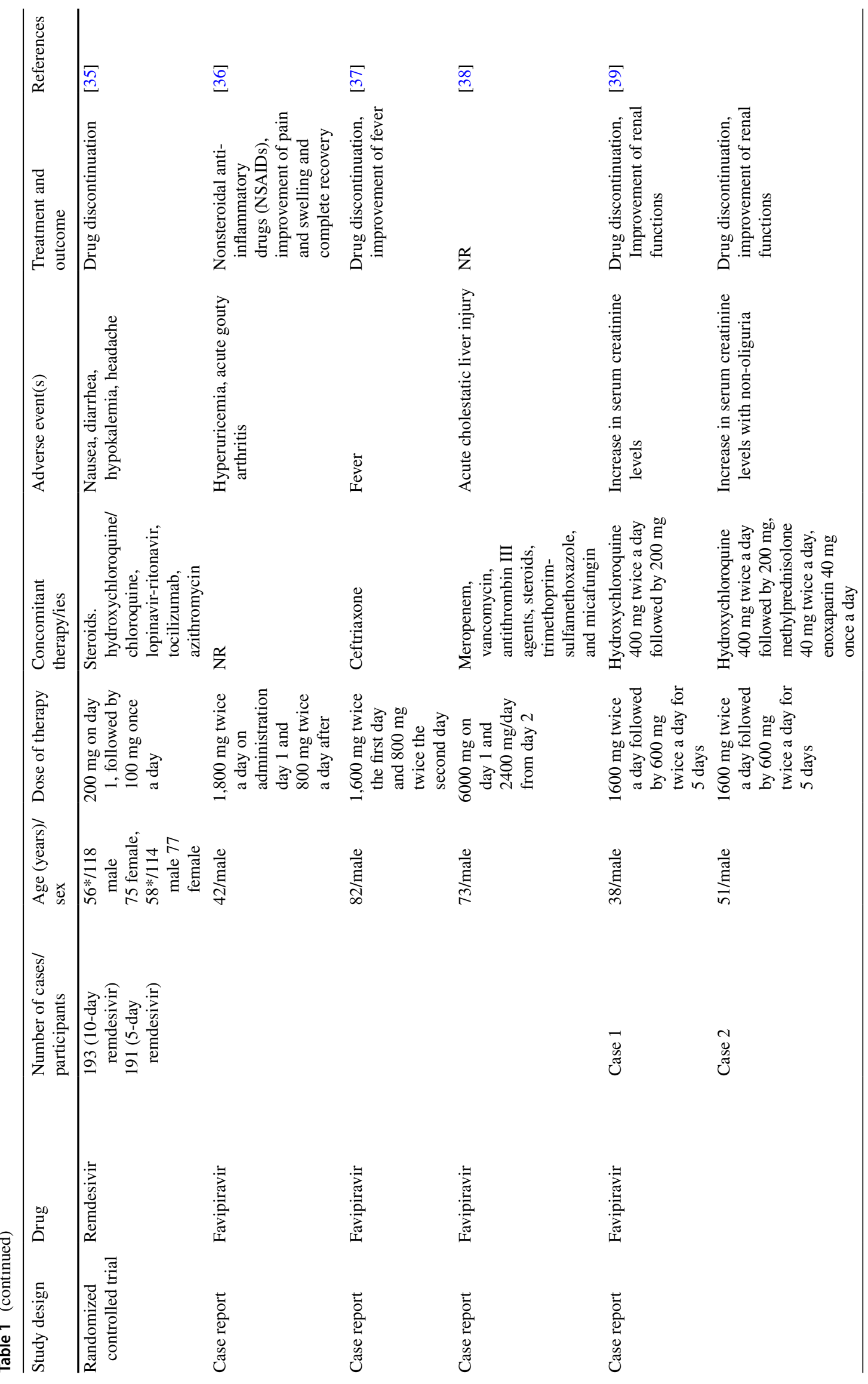




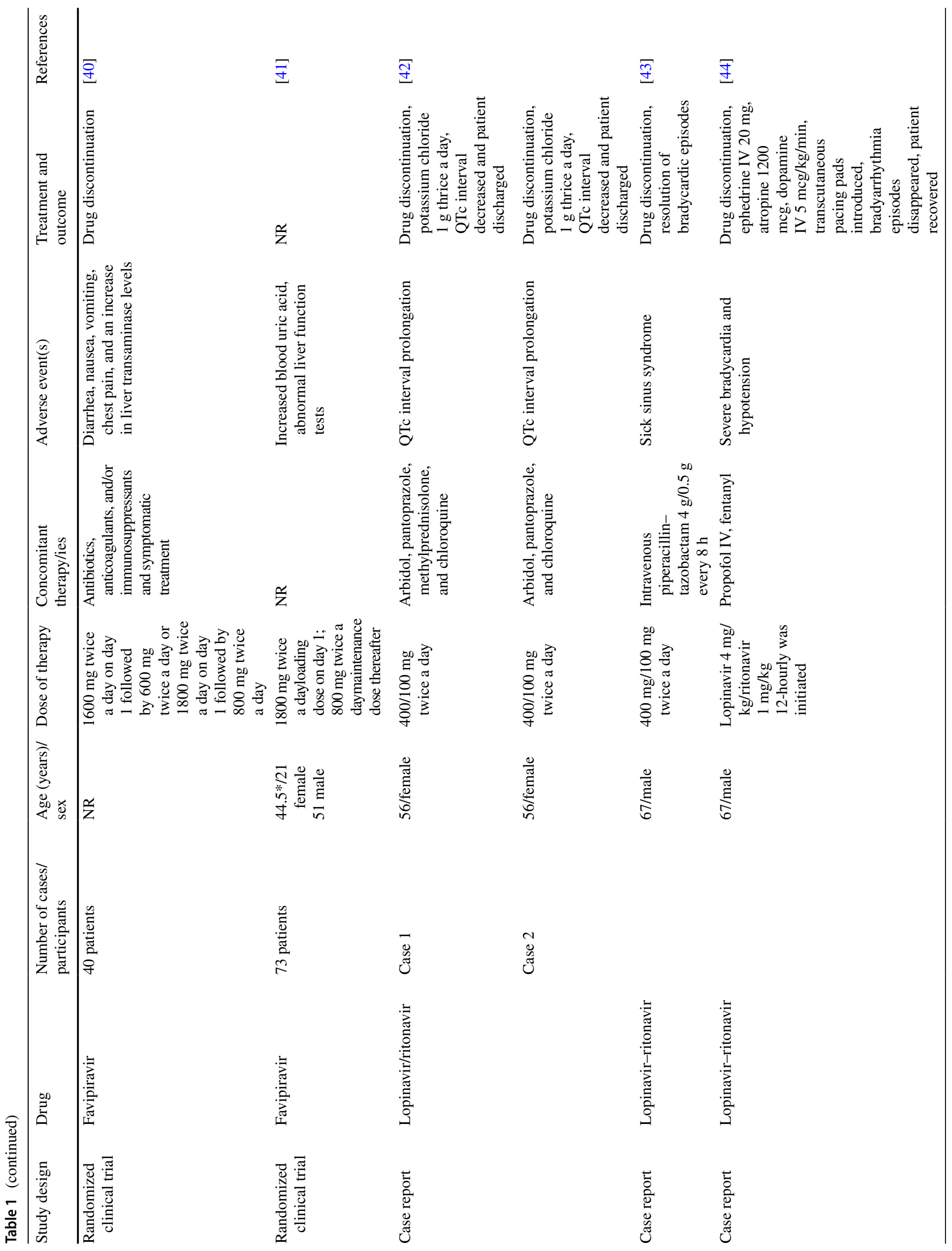




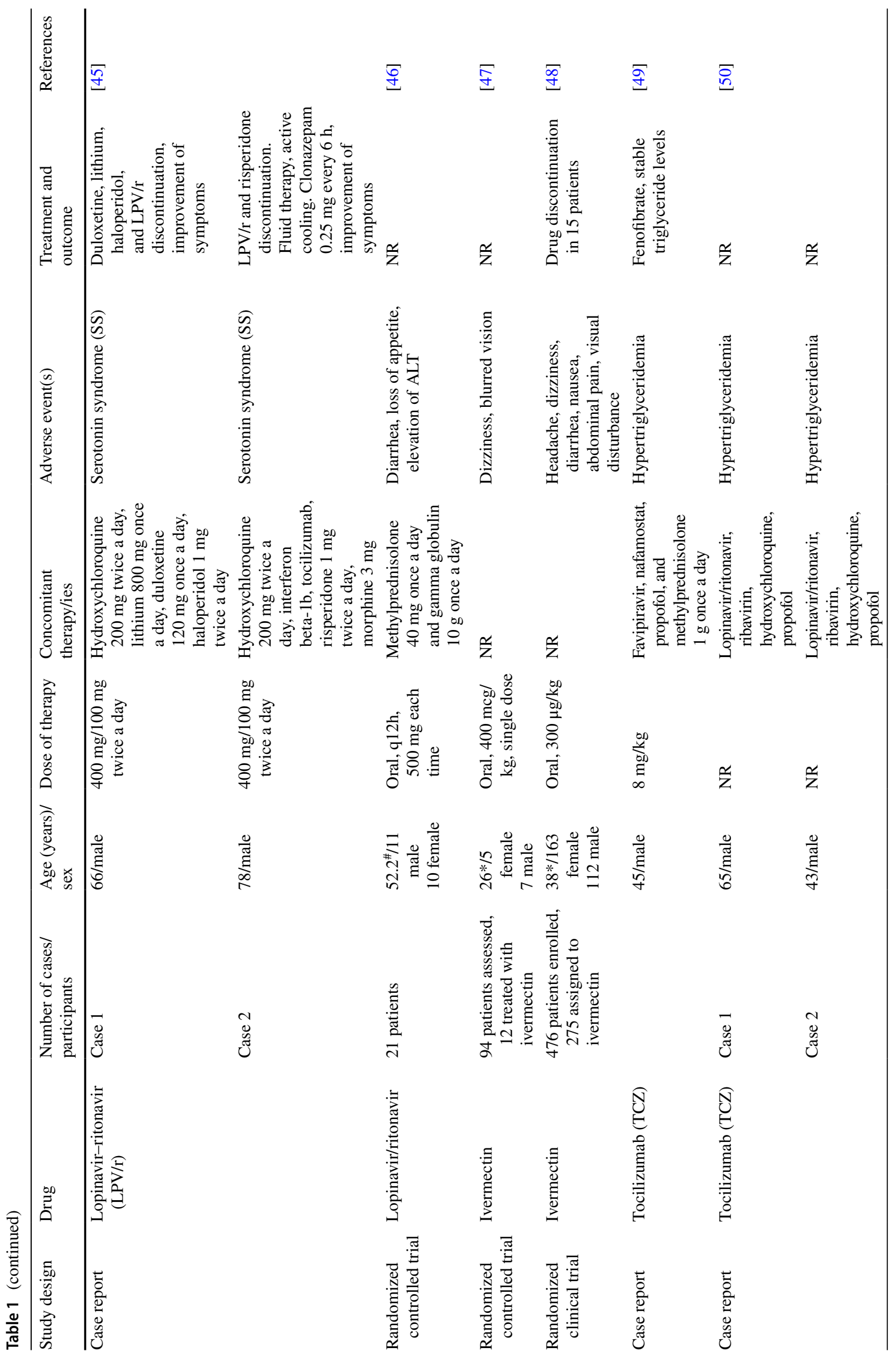




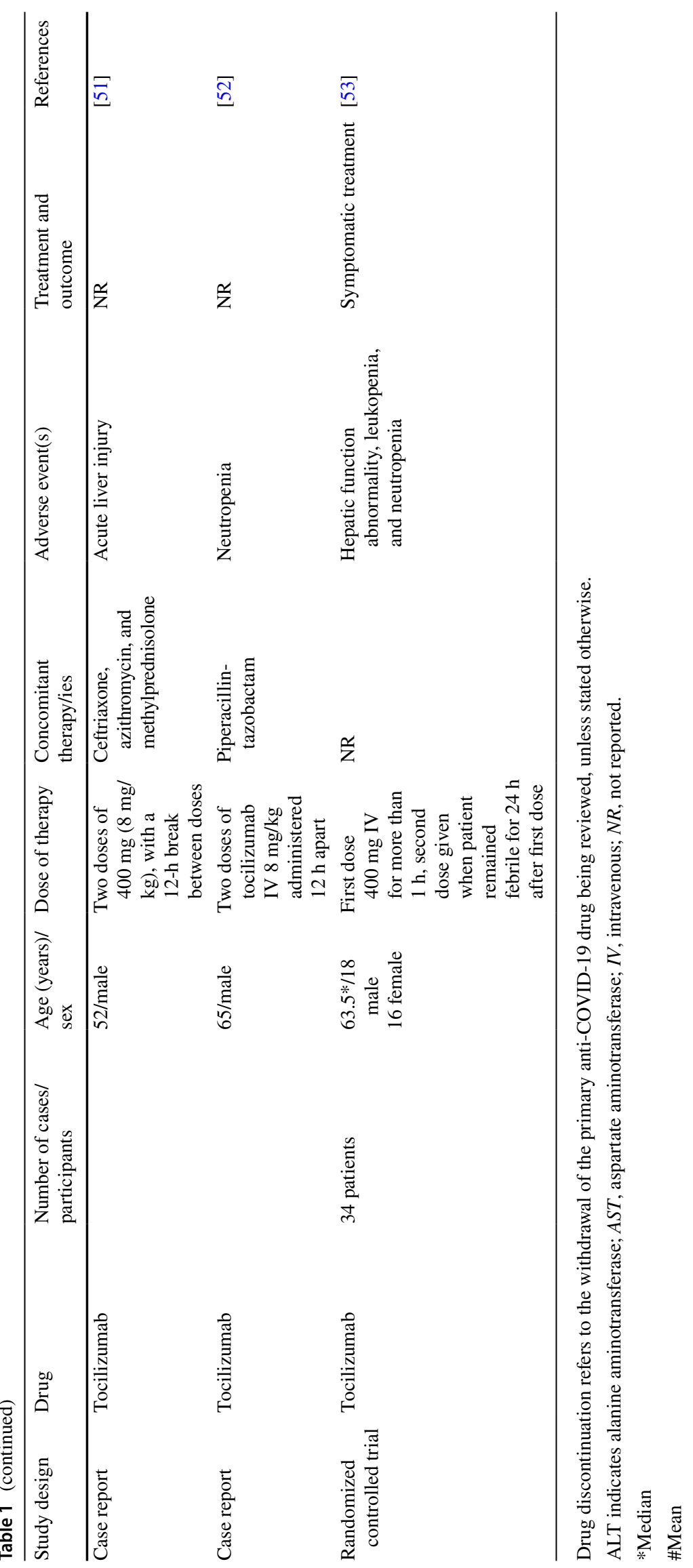

Springer 
drug. Consequently, it is advocated that a baseline ECG should be defined for patients who are planned to begin treatment with HCQ [12].

One of the most common adverse effects related to HCQ therapy is gastrointestinal disorders, mainly nausea, vomiting, diarrhea, and abdominal pain. As depicted, these are frequent, mild to moderate in nature and usually resolved following their withdrawal from the drug regime $[13,20]$. Skipper et al. [23] conducted a randomized, double-blind, placebo-controlled trial in 491 non-hospitalized patients to study the effect of HCQ treatment on disease course for early COVID-19. Of which 212 participants received hydroxychloroquine in the following dose: $800 \mathrm{mg}$ once, followed by $600 \mathrm{mg}$ in 6 to $8 \mathrm{~h}$, then $600 \mathrm{mg}$ daily for 4 more days. It was observed that $43 \%$ (92 of 212) of patients receiving HCQ experienced adverse effects in the form of upset stomach, nausea, abdominal pain, diarrhea, or vomiting as opposed to $22 \%$ (46 of 211) in the placebo category. Similarly, an openlabel, randomized, controlled trial published in May 2020 assessed the safety and efficacy of HCQ with the standard of care on 150 participants with mild or moderate COVID-19. Out of 150 patients, 70 were administrated with hydroxychloroquine for a duration of 2 to 3 weeks at a loading dose of $1200 \mathrm{mg}$ daily, followed by a maintenance dose of $800 \mathrm{mg}$ daily. The common adverse effects reported were diarrhea, vomiting, and nausea where diarrhea occurred in 7 out of 70 patients [24].

Three case reports revealed the association of hydroxychloroquine and its dermatological adverse effects. In the first case report, a 37-year-old woman was diagnosed with drug reaction with eosinophilia and systemic symptoms (DRESS) syndrome having clear clinical manifestations of skin rash, swollen face, and fever. She had been previously treated with hydroxychloroquine for suspected COVID19. Later, a positive patch test concluded HCQ was the primary cause of DRESS in the patient [18]. The second case report presented a rare case of hydroxychloroquineinduced Stevens-Johnson syndrome (SJS) of a 42-year-old woman. Following the diagnosis of adverse reaction, HCQ was substituted with lopinavir/ritonavir, and the patient was initiated with $10 \mathrm{mg}$ of loratadine twice daily and $50 \mathrm{mg}$ of diphenhydramine thrice daily for treatment. The patient was discharged from the hospital 5 days later [16]. In the third case report by Delaleu et al. [22], a 76-year-old patient manifested acute generalized exanthematous pustular (AGEP) eruptions after treatment with HCQ. The RegiSCAR score obtained for diagnosis was estimated to be 11, indicating a definite case of AGEP.

Four case reports represented other uncommon adverse events associated with the use of hydroxychloroquine. In a case report of a 29-year-old woman with severe COVID-19, hepatotoxicity related to HCQ therapy was reported. There was a tenfold increase in the serum transaminases level in the patient after HCQ administration which decreased following the withdrawal of drug [14].

Interestingly, Fernando et al. reported a case of HCQrelated ADR, where the patient underwent involuntary movements after drug administration. Though the irregular myoclonic movements completely resolved following the discontinuation of the drug, suggesting a causal relationship of HCQ and the ADR. Unlikely in this case, there exists many factors including predisposing factors, co-morbidities, and drug-drug interactions that should also be taken into consideration while determining the cause of an adverse drug reaction [17].

In addition to established data demonstrating the activation of hemolytic crisis due to COVID-19 infection in a glucose-6-phosphate dehydrogenase deficient patients, Beauverd et al. reported that hydroxychloroquine administration can further aggravate the hemolytic state in patients lacking G6PD [21].

In terms of nephrotoxicity, despite the already known long-term effect of HCQ of drug-induced renal phospholipidosis, one case addressed its occurrence with its shortterm treatment. Findings in the case displayed isometric vacuolization of the renal tubular epithelium after patient started on HCQ [25].

\section{Chloroquine}

Two cases of torsades de pointes (TdP) characterized by excessive QT prolongation (when QTc interval is $>500 \mathrm{~ms}$ ) even after discontinuation of chloroquine were reported. Szekely et al. [26] described the incidence of multiple episodes of TdP despite the withdrawal of all suspected QT prolonging agents and oral supplementation of potassium. Similar results were observed in a case by Semedo et al. [28] in which patient suffered from TdP after the suspension of chloroquine. Both the cases suggested the long half-life of chloroquine which ranges from approximately 20 to 60 days. Moreover, special emphasis on factors such as female sex, old age, existing cardiac disease, genetic predisposition, baseline QT interval, and drugs that can contribute to the increased risk for drug-induced QT prolongation should be taken into account when treating a patient with chloroquine.

In another case report published on June 2020, the authors introduced the causality of psychiatric adverse effects with chloroquine [27]. Two case reports of a 46-year-old male and 35-year-old female receiving chloroquine were reported. Psychotic symptoms like visual hallucinations, abnormal behavior, and incomprehensible speech in the former and symptoms of anxiety including uncontrollable thoughts, recurrent panic attacks, insomnia, and fear in the latter were observed. Discontinuation of drug and appropriate treatment with antipsychotic and anti-anxiety medication resulted in the disappearance of the symptoms. Although the 
mechanism of psychiatric adverse effects remains ambiguous, the authors hypothesized the effect of chloroquine on muscarinic, dopaminergic pathways alongside its antagonistic activity on 5-HT3A, 5-HT3B, and GABA receptors and agonistic action on NMDA receptors to be the trigger of such psychiatric symptoms [27].

\section{Remdesivir}

Originally synthesized by Gilead Sciences in 2017 (under the name GS-5734) for treatment against the Ebola virus, studies have shown remdesivir, a monophosphoramidate prodrug to be efficacious against various coronaviruses [60, 61]. It is a direct-acting, small molecule nucleotide analog with a broad spectrum of antiviral action [62]. An RNAdependent RNA-polymerase (RdRp) inhibitor, it prevents viral RNA synthesis due to the resemblance of its active metabolite triphosphate form (RDV-TP) to the natural adenosine triphosphate substrate and competing with it as the main substrate for RdRp [10]. In addition, it reduces the viral RNA production by disturbing the exoribonuclease activity responsible for proofreading of viral RNA, leading to RDVTP incorporation and delayed chain termination [61, 63]. As of October 22, 2020, FDA approved the use of remdesivir (Veklury) in hospitalized adults and pediatric patients with SARS-CoV-2 infection [64]. Although one of the most promising therapeutic candidates to combat COVID-19 with enough positive studies validating its effect, numerous clinical trials and reported cases have demonstrated its associated use with mild, moderate, to serious adverse effects.

Four case reports suggested the development of cardiac adverse events like sinus bradycardia and QT prolongation in COVID-19 patients under remdesivir therapy where discontinuation of the suspected drug led to the resolution of the symptoms in all five patients [29, 30, 32, 33]. Though patients were also treated with other known cardiotoxic drugs, this further supported the suspicion of remdesivir being the causative agent. Additionally, according to the Naranjo scale, one patient was given a score of 6 implying a "probable" causal relationship between remdesivir and bradycardia [29]. With regard to the first case, one possible reason can be the co-administrated drug, azithromycin, which is a QT prolonging agent. A probable mechanism behind the AE can also be the strong affinity of remdesivir for human mitochondrial RNA-polymerase, causing mitochondrial dysfunction [33]. Another can be the likeness of nucleotide triphosphate derivative, an active remdesivir metabolite to ATP leading to delayed sinoatrial node spontaneous depolarization [65]. Nevertheless, less evidence is available regarding the potential cardiac-related side effects of remdesivir and more research is needed to determine its possible mechanisms of action.
Although the information on remdesivir-induced hepatotoxicity is limited, there is evidence in the form of case reports and case series reporting incidences of increased liver enzymes in patients on remdesivir use. Leegwater et al. [31] recently reported a case of a 64-year-old man who experienced acute increased levels of ALT and AST after starting remdesivir. Remarkably, a quick fall in the ALT and AST levels were observed after immediate cessation of the drug. The authors hypothesized the drug-drug interaction between remdesivir, P-glycoprotein inhibitors as a potential cause of hepatotoxicity in the patient. Another factor for hepatotoxicity can be the temporarily administered $700 \mathrm{mg}$ of amiodarone, given 2 days after the initiation of remdesivir for new onset atrial fibrillation, since many studies depict its potential for hepatotoxicity $[66,67]$. So again drug-drug interaction leading to potentiating effect could be the reason for observed hepatotoxicity. Similarly, Carothers and colleagues published a case series of two patients describing the onset of elevated ALT and AST levels followed by acute liver failure after receiving remdesivir treatment for coronavirus disease 2019. In both cases, instant withdrawal of the drug and administration of acetylcysteine restored the ALT and AST levels to normal [34]. Likewise, it is advised by Aleen et al. to consider stopping remdesivir infusions when de novo increase in liver enzymes values is more than tenfold the upper limit of normal [68].

August 2020 published, randomized open-label trial of hospitalized patients with moderate SARS-CoV-2 infection conducted to evaluate the efficacy of remdesivir against standard care at 11 days serves as an example of other adverse events associated with remdesivir. In the trial, the median age was 56 years and patients were randomized in a 1:1:1 ratio to receive a 10-day course, a 5-day course of remdesivir, or standard care. The remdesivir patient group received a loading dose of $200 \mathrm{mg}$ followed by a maintenance dose of $100 \mathrm{mg}$ daily. In comparison, it was found that adverse events such as nausea, hypokalaemia, and headache were more frequent in the remdesivir group as compared to standard care that comprised of more serious adverse events [35]. Hence, more investigation into its safety and clinical profile is required to validate its use in the treatment of COVID-19.

\section{Favipiravir}

Favipiravir (or Avigan) is a potential antiviral drug that also acts by blocking the RNA-dependent RNA-polymerase. Developed by Fujifilm Toyama Chemical, a Japanese pharmaceutical company, it was introduced in Japan in 2014 for therapeutic use in pandemic influenza A and B virus-infected patients $[69,70]$. Similar to remdesivir, it works against a wide range of viruses such as influenza virus, ebolavirus, flavivirus, arenavirus, and coronavirus. It exhibits antiviral 
activity after entering into the host human cell [71]. Following entry, favipiravir becomes activated to form favipiravir ribofuranosyl-5'-triphosphate (favipiravir-RTP) after undergoing intracellular phosphoribosylation and phosphorylation. This activated molecule replaces the purine nucleosides and acts as a substrate for the RdRp enzyme further inhibiting the RdRp enzyme and preventing viral RNA strand elongation and protein synthesis. Additionally, lethal mutagenesis as a result of favipiravir-RTP incorporation into nascent RNA is a possible mechanism of action to stop viral infection [69, 71]. In June 2020, Glenmark Pharmaceuticals Ltd received approval from Indian regulatory authorities to manufacture and market oral favipiravir medication under the trade name "FabiFlu" for the use in mild to moderate COVID-19 patients [72]. However, to determine the adverse events safety outcome of favipiravir administration, it is still undergoing many clinical trials and clinical studies to deem its use as completely safe and effective.

Two patients experienced acute kidney injury (AKI) induced by favipiravir as reported by Nasa et al. [39]. Authors observed an increasing trend in serum creatinine levels which returned to baseline value following the cessation of favipiravir, within 5 days.

Kurita et al. [37] reported the first-ever case of an 82-year-old man with COVID-19, diagnosed with fever caused by favipiravir. The diagnosis was made after careful consideration of the clinical course and disappearance of fever, 4 days after withdrawal of the drug. Additionally, the ADR score of 6 on the Naranjo scale indicating "probable" further suggested favipiravir to be the likely cause of the adverse drug reaction.

Another rare case of favipiravir-associated acute cholestatic liver injury in a patient with a previous history of alcoholic hepatitis and compromised hepatic function was published online in December 2020. A high dose of favipiravir and its structural similarity to pyrazinamide with potential for hepatotoxicity, in addition to an already impaired hepatic function, may have precipitated the liver injury. Thus the authors recommended close monitoring of the liver function of patients treated with favipiravir, especially when administrated in high doses and with compromised liver function [38].

A case of increased uric acid levels and acute gouty arthritis after commencement of favipiravir treatment was reported in a patient with SARS-CoV-2 infection. The mechanism behind hyperuricemia could be inhibitory action on urate excretion transporters like organic anion transporter (OAT1) and OAT3, by favipiravir and favipiravir hydroxide, that prompted reduced uric acid secretion from tubules, as well as the increased reabsorption of uric acid via urate transporter by favipiravir hydroxide, altogether leading to a fall in the excretion of uric acid [36].
Similar results were observed in a randomized, comparative, open-label, multicenter, phase 3 clinical trial assessing the efficacy and safety of favipiravir in patients with mild to moderate COVID-19 illness. A loading dose of $1800 \mathrm{mg}$ twice daily on day one followed by a maintenance dose of $800 \mathrm{mg}$ of favipiravir with standard supportive care was administered to 73 patients. Overall, mainly, treatmentrelated adverse events were reported in $36 \%$ of patients ( 26 of 73). Of which, the most frequent were elevated blood uric acid levels and abnormal liver function tests that amounted to $16.4 \%$ and $6.8 \%$ of favipiravir-treated patients, respectively [41].

In phase II/III multicenter randomized clinical trial of moderate COVID-19 patients on treatment with favipiravir, the incidence of adverse effects in 17.5\% (7 of 40) participants varied among nausea, vomiting, diarrhea, chest pain, and elevated transaminases levels. The majority of the adverse drug reactions were mild to moderate in severity and caused only 2 out of 40 patients to discontinue the drug [40].

Conversely, favipiravir is mostly considered to possess a good overall safety profile with less proportion of lowgrade adverse events, having low intensity in severity [73]. Still, inadequate existing data on its positive effect against SARS-CoV-2 virus necessitates its current use for clinical studies only.

\section{Lopinavir/ritonavir}

Lopinavir is an HIV type 1 protease inhibitor used in a fixed combination with ritonavir, also a protease inhibitor that increases its plasma half-life via potent inhibition of cytochrome P450 3A4 [74, 75]. Developed by Abbott Laboratories and approved by FDA in 2000, lopinavir/ritonavir (or Kaletra) is used in combination with other antiretroviral drugs for the treatment of human immunodeficiency virus 1 (HIV-1) infection [76]. Besides the existing in vitro studies showing inhibition of SARS-CoV-1 and MERS-CoV by lopinavir/ritonavir combination, ongoing experiments and past shreds of evidence suggest its potential antiviral activity against SARSCoV-2 [77]. This drug inhibits 3-chymotrypsin-like protease activity and replication by preventing viral polyprotein cleavage, particularly gag-pol precursors, and causing the formation of immature, non-infectious virions [11, 76, 78]. In an evaluation of LOTUS China, a randomized, controlled trial by Doggrell, lopinavir/ritonavir found no favorable effects in severe patients with COVID-19 and instead induced rapid gastrointestinal adverse events. There was no significant reduction in viral RNA loads or duration of viral RNA detectability when compared to standard supportive care alone [75]. The pharmacodynamics of lopinavir/ritonavir may fail to achieve sufficient drug concentrations that can inhibit the SARS$\mathrm{CoV}-2$ proteases. 
Two cases of increased QTc interval by administration of lopinavir/ritonavir combination reported by Zhu et al. [42] provide further evidence on the relation of conduction abnormalities and antiviral drugs. In both cases, cessation of adverse effect causing drug leads to normalized QT intervals and eventual discharge from the hospital. Several independent risk factors such as female sex, drugdrug interaction, concomitant drugs like chloroquine, and electrolyte imbalance already mentioned earlier could have been the cause of QT prolongation in the two patients. Another article documented a case of 67-yearold man with pre-existing ischemic heart disease and QTc interval prolongation that increased his risk for sick sinus syndrome after treatment with lopinavir-ritonavir [43]. Severe episodes of bradyarrhythmias associated with the use of lopinavir-ritonavir were reported in a COVID-19 patient with moderate acute respiratory distress syndrome. The withdrawal of the combination drug leading to the full recovery of the patient further strengthened the causal relationship between the drug and the adverse event [44].

Serotonin syndrome is a potentially life-threatening disorder related to elevated serotonergic activity, and clinical manifestations involving myoclonic movements, tachycardia, diaphoresis, hyperreflexia, hyperthermia, and altered mental state. Serrano et al. [45] observed the earliest cases of lopinavir-ritonavir triggered serotonin syndrome in SARS-CoV-2 infected patients. The concomitancy of ritonavir with selective serotonin (SSRIs) and serotonin-norepinephrine (SNRIs) reuptake inhibitors leading to reduced elimination is the likely cause of the AE. The combination of lopinavir-ritonavir with duloxetine (SNRI), lithium, and risperidone (atypical antipsychotic), morphine in patients 1 and 2, respectively, induced the typical characteristics of serotonin syndrome.

A single center, exploratory randomized, controlled trial studying the efficacy and safety of lopinavir/ritonavir or arbidol in adult hospitalized patients having mild or moderate SARS-CoV-2 infection revealed gastrointestinal adverse effects in $23.8 \%$ of patients treated with $\mathrm{LPV} / \mathrm{r}$. Of 21 patients on LPV/r, 14.3\% (3 of 21), 9.5\% ( 2 of 21 ), and $4.8 \%$ ( 1 of 21 ) experienced diarrhea, loss of appetite, and an increase in ALT levels, respectively [46]. While in a retrospective cohort Chinese study, LPV/r in combination with umifenavir demonstrated promising outcomes in patients with COVID-19 [79, 80].

Lopinavir/ritonavir use in COVID-19 reported several adverse effects with two large randomized controlled trials in hospitalized patients with COVID-19 demonstrating no clinical benefit. Therefore, these drugs should not be used in COVID-19 patients.

\section{Ivermectin}

Ivermectin (IVM), primarily an anti-helminthic drug, is used for the treatment of plethora of parasitic infections including onchocerchiasis, strongyloidiasis, head lice, scabies, lymphatic filariasis, ascariasis, entrobiasis, rosacea, and trichuriasis. However, apart from its anti-parasitic activity, IVM has also exhibited broad spectrum antiviral characteristics in vitro [81]. It exerts an inhibitory action on RNA replication in several positive, single-stranded RNA viruses such as dengue virus, human immunodeficiency virus 1 , influenza virus, and Zika virus as a nuclear transport inhibitor and interferes in the interaction between importin $\alpha / \beta 1$-mediated nuclear import and integrase protein, crucial for viral infection [82]. While several studies have demonstrated its efficacy in decreasing the mortality rate, reducing the viral load, and improving patient recovery time in individuals with severe COVID-19 [83, 84], large well-conducted clinical trials have concluded its inefficiency in treatment of COVID19 patients. The common adverse effects related to IVM treatment include headache, dizziness, rash, and nausea.

According to a pilot, double-blind, placebo-controlled, randomized clinical trial conducted by Chaccour et al. [47] to determine the effect of single-dose IVM on mild COVID19 patients having no risk factors in comparison to placebo, improved clinical outcome and reduced viral load was observed. In ivermectin-treated group, no serious adverse events were reported apart from the common adverse events, namely, dizziness and blurred vision.

A double-blind, randomized clinical trial was held from July 15 to December 21, 2020, on 476 patients to ascertain the efficacy of IVM administration in mild COVID-19 patients. IVM patient group received a dose $300 \mu \mathrm{g} / \mathrm{kg}$ of body weight each day for 5 days continuously. Both solicited and serious adverse events were accounted, though not much significant differences were observed in the frequency of adverse events on comparing IVM-treated group (76.7\%) to placebo group (81.3\%). The most common adverse events reported in IVM group were headache, dizziness, diarrhea, and nausea accounting for $50.9 \%, 35.6 \%, 30.2 \%$, and $24.0 \%$ of total AEs, respectively [48].

Nevertheless, human studies involving clinical trials on a larger scale are required to further corroborate its safety and efficacy profile for use against SARS-CoV-2 virus.

\section{Tocilizumab}

Tocilizumab, an interleukin-6 receptor antagonist, is a recombinant humanized monoclonal antibody currently being used for the treatment of severe COVID-19, primarily in patients at risk of cytokine storms [85]. Approved by FDA 
for use in rheumatoid arthritis, juvenile idiopathic arthritis, giant cell arteritis, and chimeric antigen receptor (CAR) T cell therapy-induced cytokine release syndrome (CRS), it exhibits immunomodulatory and anti-inflammatory effects $[86,87]$. Its mechanism of action involves disruption in the signal transduction cascade (classical and trans-signalling pathway) by binding with IL-6 receptor and interrupting its interaction with IL-6, thereby decreasing the release of proinflammatory cytokines $[87,88]$. In a retrospective observational study comprising of 30 severe or critically ill hospitalized COVID-19 patients under treatment with TCZ, it was observed that TCZ is a potent therapeutic candidate for severe COVID-19 patients characterized by elevated IL-6 levels. It was found to have reduced the disease mortality and clinical course of the patients [89]. Tocilizumab use is associated with many complications. In particular, increased triglycerides, elevated liver enzymes, nausea, neutropenia, headache, dizziness, mouth ulcerations, and upper abdominal pain are some of the frequent adverse effects related to its administration [90].

Nakamura et al. [49] presented a case of 45-year-old male with elevated triglyceride levels following TCZ administration. Notably, only after a short duration of TCQ treatment, a sharp increase in the TG levels was detected. Thus, suggesting the involvement with severe inflammatory response provoked by COVID-19 in the dramatic surge. IL-6 has an essential function in mobilizing free fatty acids through adipocytes and stimulating glucose and free fatty acid uptake from serum by skeletal muscles. Similar findings were observed in two cases where patients exhibited a peak increase in serum TG levels after TCZ treatment for acute severe respiratory distress syndrome (ARDS). The Naranjo Adverse Drug Reaction Probability Scale gave a score of 7, denoting a probable relationship between hypertriglyceridemia and tocilizumab. According to Morrison et al. [50], the effect of TCZ on the metabolic pathways through inhibition of IL-6 receptor can lead to an increase in triglycerides level. Furthermore, the concurrent use of propofol can be another cause contributing to the worsening of hypertriglyceridemia.

Hepatotoxicity is a rare but serious complication associated with TCZ therapy. Muhović et al. [51] observed the first case of drug-induced liver injury induced by TCZ in a patient with severe COVID-19 infection. The authors noted a 40-fold increase in the transaminases level, $24 \mathrm{~h}$ after the patient received two doses of TCZ. The causal relationship of DILI by tocilizumab was given a score of 8 points and deemed "probable" as per the Council for International Organizations of Medical Sciences/Roussel Uclaf Causality Assessment Method (CIOMS/RUCAM).

In one case report, TCZ induced severe, persistent neutropenia in a positive COVID-19 patient was detailed. Despite the lack of proper evidence to form a causal relationship between TCQ and severe, prolonged neutropenia, the authors suspected the neutropenic influence of $\mathrm{TCZ}$, in this case, to have been augmented by the concomitant genetic factor [52].

A recent randomized, controlled, open-label, multicenter trial of 65 participants supported similar findings. Among the TCZ-treated patients, common adverse effects observed were abnormal hepatic function (6 of 34), leukopenia (5/34), and neutropenia (3/35). Also, it was established that the observed adverse events either resolved spontaneously or after symptomatic care [53].

In the randomized controlled open-label RECOVERY (Randomised Evaluation of COVID-19 Therapy) clinical trial, originally conducted in UK, the effects of different therapeutics including dexamethasone, tocilizumab, hydroxychloroquine, lopinavir/ritonavir, corticosteroids, or azithromycin were evaluated in hospitalized COVID19 patients. The large RECOVERY trial, however, did not publish significant safety data and is still under investigation. The trial has also been launched in four other countries including Indonesia, Nepal, Vietnam, and South Africa [91-93].

Substantial clinical trials such as the SOLIDARITY and DisCoVeRy trial accessing the clinical outcomes of repurposed drugs in COVID-19 patients have enormously contributed in determining the safety and efficacy of these drugs against the SARS-CoV-2 virus. Drugs including hydroxychloroquine, lopinavir, and ivermectin are deemed to be inefficient on the basis of overall mortality, duration of hospital stay, and initiation of ventilation, whereas drugs such as remdesivir, tocilizumab, and dexamethasone are recommended to be used for certain conditions owing to few, sufficiently powered, positive studies, indicating their favorable effects. The effective use of chloroquine and favipiravir, however, is yet to be ascertained on account of insufficient data, allowing their use in clinical studies only so far $[11,94,95]$.

\section{Limitations}

There are several limitations to this review. To begin with, the number of case reports, case series, and random clinical trials describing the relation of adverse effects to antiviral COVID-19 therapy is inadequate. Due to this, the results of this review should be understood cautiously. This may be because only publications in the English language were incorporated and unpublished literature was not investigated. Underreporting of adverse effects may be another reason for less available evidence. Additionally, these are often a subject of bias with the information obtained from them being incomplete, or incorrect, and resulting in selective reporting and possible publication bias. 


\section{Conclusion}

In conclusion, there are several adverse drug events induced by various repurposed drugs used against COVID-19 disease, as supported by the collected evidence. Although most are self-limiting and mild to moderate in severity, these can be severe or life-threatening events with confounding factors that demand immediate attention either necessitating prompt discontinuation of the suspected drug or administration of counter medication. Large clinical studies, including the SOLIDARITY and DisCoVeRy trials, have demonstrated the ineffectiveness of drugs such as hydroxychloroquine, lopinavir/ritonavir, and ivermectin on the grounds of overall mortality, duration of hospital stay, initiation of ventilation, and dissuading their administration in COVID-19 patients. These drugs should neither be used as routine medication nor in the case of clinical studies. But for drugs including remdesivir, tocilizumab, and dexamethasone, there are enough, sufficiently powered, positive studies that have recommended their use in the case of patients in specific critical conditions or special circumstances [11, 94, 95]. Studies proving the effectiveness of chloroquine or favipiravir, however, are still inconclusive. And since the data is insufficient to form a reliable conclusion, presently, these drugs should be used in clinical studies only.

Clinicians should be careful before administering any drug and consider weighing the risk versus benefits related to its use. And while the majority of the observed reports propose the causal relationship of COVID-19 drugs and their adverse effects as "probable," there are several other factors that can affect the safety and effectiveness of a drug. Concomitant medications with their own propensity to induce the adverse effects or drug-drug interactions being two such major factors. Furthermore, vigilant drug monitoring and prompt reporting of any adverse effects are recommended for quick counter interventions to be undertaken. Thus, to gain a greater comprehension of adverse events, their mechanisms, and other potential risk factors, more research and clinical studies into drug-adverse event causality relationship and epidemiology are necessary.

Acknowledgements Authors wish to thank the University Institute of Pharmaceutical Sciences (UIPS), Panjab University, Chandigarh for coordination, help, and timely support in preparing the manuscript.

Author contribution All authors contributed to the study conception and design. Mei Nee Chiu performed the data collection and analysis and drafted the manuscript. Mei Nee Chiu and Maitry Bhardwaj participated in the literature discussion. Sangeeta Pilkhwal Sah revised the manuscript. All authors read and approved the final manuscript.

Data availability Not applicable.

Code availability Not applicable.

\section{Declarations}

Ethics approval Not applicable.

Consent to participate Not applicable.

Consent for publication Not applicable.

Conflict of interest The authors declare no competing interests.

\section{References}

1. Ven Venkatasubbaiah M, Reddy PD, Satyanarayana SV (2020) Literature-based review of the drugs used for the treatment of COVID-19. Current medicine research and practice 10(3):100 109. https://doi.org/10.1016/j.cmrp.2020.05.013

2. WHO (2021) W.H.O. WHO coronavirus (COVID-19) dashboard. https://covid19.who.int/. Accessed 14 June 2021

3. Singh TU, Parida S, Lingaraju MC et al (2020) Drug repurposing approach to fight COVID-19. Pharmacol Rep 72:1479-1508

4. Tarighi P, Eftekhari S, Chizari, et al (2021) A review of potential suggested drugs for coronavirus disease (COVID-19) treatment. Eur J Pharmacol 895:173890. https://doi.org/10.1016/j.ejphar. 2021.173890

5. Crescioli G, Brilli V, Lanzi C et al (2021) Adverse drug reactions in SARS-CoV-2 hospitalised patients: a case-series with a focus on drug-drug interactions. Intern Emerg Med 16(3):697-710. https://doi.org/10.1007/s11739-020-02586-8

6. Desai MK (2020) Pharmacovigilance and assessment of drug safety reports during COVID 19. Perspectives in clinical research 11(3):128. https://doi.org/10.4103/picr.PICR_171_20

7. Atzrodt CL, Maknojia I, McCarthy RDP et al (2020) A guide to COVID-19: a global pandemic caused by the novel coronavirus SARS-CoV-2. FEBS J 287(17):3633-3650. https://doi.org/10. $1111 /$ febs. 15375

8. Yousefi H, Mashouri L, Okpechi SC et al (2020) Repurposing existing drugs for the treatment of COVID-19/SARS-CoV-2 infection: a review describing drug mechanisms of action. Biochem Pharmacol 183:114296. https://doi.org/10.1016/j.bcp.2020. 114296

9. Türsen Ü, Türsen B, Lotti T (2020) Cutaneous side-effects of the potential COVID-19 drugs. Dermatol Ther 33(4):e13476. https:// doi.org/10.1111/dth. 13476

10. Liu D, Zeng X, Ding Z et al (2021) Adverse cardiovascular effects of anti-COVID-19 drugs. Front Pharmacol 12:699949. https://doi. org/10.3389/fphar.2021.699949

11. RECOVERY Collaborative Group (2021) Dexamethasone in hospitalized patients with Covid-19. N Engl J Med 384(8):693-704. https://doi.org/10.1056/NEJMoa2021436

12. Zengin R, Sarikaya ZT, Karadağ Net al (2020) Adverse cardiac events related to hydroxychloroquine prophylaxis and treatment of COVID-19. Infect Dis Clin Microbiol 2(1):24-26. https://doi. org/10.36519/idcm.2020.0012

13. Abdelmaseih R, AbdelmasihR HM et al (2020) Serious adverse events associated with hydroxychloroquine amidst COVID-19 pandemic: case series and literature review. Cureus 12(6):e8415. https://doi.org/10.7759/cureus.8415

14. Falcão MB, Cavalcanti LP, Filho NMF et al (2020) Case report: hepatotoxicity associated with the use of hydroxychloroquine in a patient with COVID-19. Am J Trop Med Hyg 102(6):1214-1216. https://doi.org/10.4269/ajtmh.20-0276

15. Kang Y, Wang H, Chen $\mathrm{H}$ et al (2020) Suspected hydroxychloroquineinduced sinus bradycardia and QTc prolongation in a patient with 
COVID-19. Int Heart J 61(5):1056-1058. https://doi.org/10.1536/ihj. 20-271

16. Davoodi L, Jafarpour H, Kazeminejad Aet al (2020) Hydroxychloroquine-induced Stevens-Johnson syndrome in COVID-19: a rare case report. Oxf Med Case Reports (6): omaa042. https://doi.org/10.1093/ omcr/omaa042

17. Fernando EZ, Yu JRT, Santos SMA et al (2021) Involuntary movements following administration of hydroxychloroquine for COVID-19 pneumonia. J Mov Disord 14(1):75-77. https://doi. org/10.14802/jmd.20091

18. Castro Jiménez A, Navarette NN, Gomez ARG et al (2021) First case of DRESS syndrome caused by hydroxychloroquine with a positive patch test. Contact Dermatitis 84(1):50-51. https://doi. org/10.1111/cod.13657

19. Asli R, Abdullah MS, Chong PL et al (2020) Case report: right bundle brunch block and QTc prolongation in a patient with COVID-19 treated with hydroxychloroquine. Am J Trop Med Hyg 103(1):79-82. https://doi.org/10.4269/ajtmh.20-0376

20. Patel J, Patel R, Rodriguez L et al (2020) Cardiovascular considerations of experimental hydroxychloroquine therapy on patients diagnosed with COVID-19: a case series review. Cureus 12(7):e9151. https://doi.org/10.7759/cureus.9151

21. Beauverd Y, Adam Y, Assouline B et al (2020) COVID-19 infection and treatment with hydroxychloroquine cause severe haemolysis crisis in a patient with glucose-6-phosphate dehydrogenase deficiency. Eur J Haematol 105(3):357-359. https://doi.org/10. 1111/ejh.13432

22. Delaleu J, Deniau B, Battistella M et al (2020) Acute generalized exanthematous pustulosis induced by hydroxychloroquine prescribed for COVID-19. J Allergy Clin Immunol Pract. 8(8): 2777-2779. https://doi.org/10.1016/j.jaip.2020.05.046

23. Skipper CP, Pastick KA, Engen NW et al (2020) Hydroxychloroquine in nonhospitalized adults with early COVID-19: a randomized trial. Ann Intern Med 173(8):623-631. https://doi.org/10. 7326/M20-4207

24. Tang W, Cao Z, Han M et al (2020) Hydroxychloroquine in patients with mainly mild to moderate coronavirus disease 2019: open label, randomised controlled trial. bmj 369. https://doi.org/ 10.1136/bmj.m1849

25. Obeidat M, Isaacson AL, Chen SJ et al (2020) Zebra-like bodies in COVID-19: is phospholipidosis evidence of hydroxychloroquine induced acute kidney injury? Ultrastruct Pathol 44(4-6):519-523. https://doi.org/10.1080/01913123.2020.1850966

26. Szekely Y, Lichter Y, Shrkihe BA et al (2020) Chloroquineinduced torsades de pointes in a patient with coronavirus disease 2019. Heart Rhythm 17(9):1452-1455. https://doi.org/10.1016/j. hrthm.2020.04.046

27. Benjelloun R, Otheman Y, Kettani CE (2020) Psychiatric side effects of chloroquine in COVID-19 patients: two case reports. Pan Afr Med J. 35(Suppl 2):83. https://doi.org/10.11604/pamj. supp.2020.35.24064

28. Semedo E, Kapel GF, Opstal JV et al (2020) Drug-induced 'torsade de pointes' in a COVID-19 patient despite discontinuation of chloroquine. Importance of its long half-life: a case report. European Heart Journal-Case Reports 4(FI1):1-5.https://doi.org/ 10.1093/ehjcr/ytaa218

29. Day LB, Abdel-Qadir H, Fralick M (2021) Bradycardia associated with remdesivir therapy for COVID-19 in a 59-year-old man. CMAJ 193(17):E612-E615. https://doi.org/10.1503/cmaj. 210300

30. Gupta AK, Parker BM, Priyadarshi V et al (2020) Cardiac adverse events with remdesivir in COVID-19 infection. Cureus 12(10):e11132. https://doi.org/10.7759/cureus.11132

31. Leegwater E, Strik A, Wilms EB et al (2021) Drug-induced liver injury in a patient with coronavirus disease 2019: potential interaction of remdesivir with P-glycoprotein inhibitors. Clin Infect Dis 72(7):1256-1258. https://doi.org/10.1093/cid/ciaa883

32. Gubitosa JC, Kakar P, Gerula C et al (2020) Marked sinus bradycardia associated with remdesivir in COVID-19: a case and literature review. JACC Case Rep 2(14):2260-2264

33. Barkas F, Styla CP, Bechlioulis A et al (2021) Sinus bradycardia associated with remdesivir treatment in COVID-19: a case report and literature review. J Cardiovasc Dev Dis 8(2):18. https://doi. org/10.3390/jcdd8020018

34. Carothers C, Birrer K, Vo M (2020) Acetylcysteine for the treatment of suspected remdesivir-associated acute liver failure in COVID-19: a case series. Pharmacotherapy 40(11):1166-1171. https://doi.org/10.1002/phar.2464

35. Spinner CD, Gottlieb RL, Criner GJ et al (2020) Effect of remdesivir vs standard care on clinical status at 11 days in patients with moderate COVID-19: a randomized clinical trial. JAMA 324(11):1048-1057. https://doi.org/10.1001/jama.2020.16349

36. Hase R, Kurata R, Ishida K et al (2020) Acute gouty arthritis during favipiravir treatment for coronavirus disease 2019. Intern Med 59(18):2327-2329. https://doi.org/10.2169/internalmedicine. 5377-20

37. Kurita T, Ishida K, Muranaka E et al (2020) A favipiravir-induced fever in a patient with COVID-19. Intern Med 59(22):2951-2953. https://doi.org/10.2169/internalmedicine.5394-20

38. Yamazaki S, Suzuki T, Sayama M et al (2021) Suspected cholestatic liver injury induced by favipiravir in a patient with COVID19. J Infect Chemother 27(2):390-392. https://doi.org/10.1016/j. jiac.2020.12.021

39. Nasa P, Shrivastava P, Kulkarni A et al (2021) Favipiravir induced nephrotoxicity in two patients of COVID-19. J Assoc Physicians India 69:88

40. Ivashchenko AA, Dmitriev KA, Vostokova NV et al (2020) AVIFAVIR for treatment of patients with moderate COVID-19: interim results of a phase II/III multicenter randomized clinical trial. medRxiv. https://doi.org/10.1101/2020.07.26.20154724

41. Udwadia ZF, Singh P, Barkate H et al (2021) Efficacy and safety of favipiravir, an oral RNA-dependent RNA polymerase inhibitor, in mild-to-moderate COVID-19: a randomized, comparative, open-label, multicenter, phase 3 clinical trial. International Journal of Infectious Diseases 103:62-71.https://doi.org/10.1016/j.ijid. 2020.11.142

42. Zhu S, Wang J, Wang Y et al (2020) QTc prolongation during antiviral therapy in two COVID-19 patients. J Clin Pharm Ther 00:1-4. https://doi.org/10.1111/jcpt.13183

43. Wang LY, Ng GYP (2020) COVID-19 treatment with lopinavirritonavir resulting in sick sinus syndrome: a case report. Eur Heart J Case Rep 4(FI1):1-6. https://doi.org/10.1093/ehjcr/ytaa171

44. Shree V, Liew LQE, Teo WW et al (2020) Potentially fatal severe brady arrythmias related to lopinavir-ritonavir in a COVID 19 patient. J Microbiol Immunol Infect 54(1):133-135. https://doi. org/10.1016/j.jmii.2020.07.015

45. Serrano MM, Pérez-Sánchez JR, Sánchez SP et al (2020) Serotonin syndrome in two COVID-19 patients treated with lopinavir/ ritonavir. J Neurol Sci 415:116944. https://doi.org/10.1016/j.jns. 2020.116944

46. Li Y, Xie Z, Lin W et al (2020) An exploratory randomized, controlled study on the efficacy and safety of lopinavir/ritonavir or arbidol treating adult patients hospitalized with mild/moderate COVID-19 (ELACOI). MedRxiv. https://doi.org/10.1101/2020. 03.19.20038984

47. Chaccour C, Casellas A, Blanco-Di Matteo A et al (2020) The effect of early treatment with ivermectin on viral load, symptoms and humoral response in patients with mild COVID-19: a pilot, double-blind, placebo-controlled, randomized clinical trial. https://doi.org/10.21203/rs.3.rs-116547/v1 
48. López-Medina E, López P, Hurtado IC et al (2021) Effect of ivermectin on time to resolution of symptoms among adults with mild COVID-19: a randomized clinical trial. JAMA 325(14):14261435. https://doi.org/10.1001/jama.2021.3071

49. Nakamura H, Miyagi K, Otsuki M et al (2021) Acute hypertriglyceridaemia caused by tocilizumab in a patient with severe COVID-19. Intern Med 59(22):2945-2949. https://doi.org/10. 2169/internalmedicine.5244-20

50. Morrison AR, Johnson JM, Ramesh M et al (2020) Acute hypertriglyceridemia in patients with COVID-19 receiving tocilizumab. J Med Virol 92(10):1791-1792. https://doi.org/10.1002/jmv.25907

51. Muhović D, Bojović J, Bulatović A et al (2020) First case of druginduced liver injury associated with the use of tocilizumab in a patient with COVID-19. Liver Int 40(8):1901-1905. https://doi. org/10.1111/liv.14516

52. Bernardo L, Sesto Del S, Giordano L et al (2020) Severe prolonged neutropenia following administration of tocilizumab in a patient affected by COVID-19: A case report and brief review of the literature. Drugs \& Therapy Perspectives 1-5 https://doi.org/ 10.1007/s40267-020-00777-z

53. Wang D, Fu B, Peng Z et al (2021) Tocilizumab in patients with moderate or severe COVID-19: a randomized, controlled, openlabel, multicenter trial. Front Med 1-9 https://doi.org/10.1007/ s11684-020-0824-3

54. Sinha N, Balayla G (2020) Hydroxychloroquine and COVID19. Postgrad Med J 96(1139):550-555. https://doi.org/10.1136/ postgradmedj-2020-137785

55. Li X, Wang Y, Agostinis P et al (2020) Is hydroxychloroquine beneficial for COVID-19 patients? Cell Death Dis 11:1-6. https:// doi.org/10.1038/s41419-020-2721-8

56. Meyerowitz EA, Vannier AGL, Friesen MGN et al (2020) Rethinking the role of hydroxychloroquine in the treatment of COVID-19. FASEB J 34(5):6027-6037. https://doi.org/10.1096/ fj. 202000919

57. Satarker S, Ahuja T, Banerjee M et al (2020) Hydroxychloroquine in COVID-19: potential mechanism of action against SARSCoV-2. Current Pharmacology Reports 6:203-211. https://doi.org/ 10.1007/s40495-020-00231-8

58. Yao X, Ye F, Zhang M et al (2020) In vitro antiviral activity and projection of optimized dosing design of hydroxychloroquine for the treatment of severe acute respiratory syndrome coronavirus 2 (SARS-CoV-2). Clin Infect Dis 71(15):732-739. https://doi.org/ 10.1093/cid/ciaa237

59. Liu J, Cao R, Xu M et al (2020) Hydroxychloroquine, a less toxic derivative of chloroquine, is effective in inhibiting SARS-CoV-2 infection in vitro. Cell discovery 6(1):1-4. https://doi.org/10.1038/ s41421-020-0156-0

60. Al-Tawfiq JA, Al-Homoud AH, Memish ZA (2020) Remdesivir as a possible therapeutic option for the COVID-19. Travel Med Infect Dis 34:101615. https://doi.org/10.1016/j.tmaid.2020.101615

61. Gordon CJ, Tchesnokov EP, Woolner E et al (2020) Remdesivir is a direct-acting antiviral that inhibits RNA-dependent RNA polymerase from severe acute respiratory syndrome coronavirus 2 with high potency. J Biol Chem 295(20):6785-6797. https://doi.org/10. 1074/jbc.RA120.013679

62. Malin JJ, Suárez I, Priesner V et al (2021) Remdesivir against COVID-19 and other viral diseases. Clinical microbiology reviews 34(1). https://doi.org/10.1128/CMR.00162-20

63. Al-Tannak NF, Novotny L, Alhunayan A (2020) Remdesivirbringing hope for COVID-19 treatment. Sci Pharm 88(2):29. https://doi.org/10.3390/scipharm88020029

64. FDA approves first treatment for COVID-19 administration (2020) U.S.F.a.D. https://www.fda.gov/news-events/press-announcements/ fda-approves-first-treatment-covid-19. Accessed 6 June 2021

65. Touafchia A, Bagheri H, Carrié D et al (2021) Serious bradycardia and remdesivir for coronavirus 2019 (COVID-19): a new safety concerns. Clinical Microbiology and Infection 27(5):791. e5-791. e8. https://doi.org/10.1016/j.cmi.2021.02.013

66. LiverTox: clinical and research information on drug-induced liver injury [Internet]. Bethesda (MD): National Institute of Diabetes and Digestive and Kidney Diseases (2016) Amiodarone.https://www.ncbi.nlm.nih.gov/books/NBK548109/. Accessed 8 November 2021

67. LiverTox: clinical and research information on drug induced liver injury [Internet]. Bethesda (MD): National Institute of Diabetes and Digestive and Kidney Diseases (2020) Remdesivir. https://www.ncbi.nlm.nih.gov/books/NBK564049/. Accessed 8 November 2021

68. Aleem A, Mahadevaiah G, Shariff N et al (2021) Hepatic manifestations of COVID-19 and effect of remdesivir on liver function in patients with COVID-19 illness. in Baylor University Medical Center Proceedings. Taylor \& Francis 34(4):473-477. https://doi.org/10.1080/08998280.2021.1885289

69. Hashemian SM, Farhadi T, Velayati AA (2020) A review on favipiravir: the properties, function, and usefulness to treat COVID-19. Expert review of anti-infective therapy 19(8):1029 1037 .https://doi.org/10.1080/14787210.2021.1866545

70. Joshi S, Parkar J, Ansari A et al (2020) Role of favipiravir in the treatment of COVID-19. Int J Infect Dis 102:501-508. https:// doi.org/10.1016/j.ijid.2020.10.069

71. Agrawal U, Raju R, Udwadia ZF (2020) Favipiravir: a new and emerging antiviral option in COVID-19. Medical Journal Armed Forces India 76(4):370-376. https://doi.org/10.1016/j. mjafi.2020.08.004

72. Reuters (2020) Glenmark gets India approval for favipiravir as COVID-19 treatment. https://www.reuters.com/article/ us-health-coronavirus-glenmark-pharms-idUSKBN23Q2E9. Accessed 6 June 2021

73. Kaur RJ, Charan J, Dutta S et al (2020) Favipiravir use in COVID-19: analysis of suspected adverse drug events reported in the WHO database. Infection and drug resistance 13:4427. https://doi.org/10.2147/IDR.S287934

74. Magro P, Zanella I, Pescarolo M et al (2020) Lopinavir/ritonavir: repurposing an old drug for HIV infection in COVID-19 treatment. J Biomed 44(1):43-53. https://doi.org/10.1016/j.bj. 2020.11.005

75. Doggrell SA (2020) Does lopinavir measure up in the treatment of COVID-19? Expert Opin Investig Drugs 29(8):793-796. https://doi.org/10.1080/13543784.2020.1777277

76. Qu J, Li GH, Wang JJ et al (2021) Comparative effectiveness of lopinavir/ritonavir-based regimens in COVID-19. Clin Exp Pharmacol Physiol 48(2):203-210. https://doi.org/10.1111/ 1440-1681.13425

77. Kim JW, Kim EJ, Kwon HH et al (2021) Lopinavir-ritonavir versus hydroxychloroquine for viral clearance and clinical improvement in patients with mild to moderate coronavirus disease 2019. Korean J Intern Med 36(Suppl 1):S253. https:// doi.org/10.3904/kjim.2020.224

78. Salvi R, Patankar P (2020) Emerging pharmacotherapies for COVID-19. Biomed Pharmacother 128:110267. https://doi.org/ 10.1016/j.biopha.2020.110267

79. Costanzo M, De Giglio MA, Roviello GN (2020) SARS-CoV-2: recent reports on antiviral therapies based on lopinavir/ritonavir, darunavir/umifenovir, hydroxychloroquine, remdesivir, favipiravir and other drugs for the treatment of the new coronavirus. Curr Med Chem 27(27):4536-4541. https://doi.org/10.2174/ 0929867327666200416131117

80. von Hentig N (2021) Repositioning HIV protease inhibitors and nucleos(t)ide RNA polymerase inhibitors for the treatment of SARS-CoV-2 infection and COVID-19. Eur J Clin Pharmacol 77(9):1297-1307. https://doi.org/10.1007/ s00228-021-03108-x 
81. Dixit A, Yadav R, Singh AV (2020) Ivermectin: potential role as repurposed drug for COVID-19. The Malaysian journal of medical sciences: MJMS 27(4):154. https://doi.org/10.21315/mjms2020. 27.4.15

82. Wehbe Z, Wehbe M, Iratni R et al (2021) Repurposing ivermectin for COVID-19: molecular aspects and therapeutic possibilities. Front Immunol 12:1040. https://doi.org/10.3389/fimmu.2021. 663586

83. Okumuş N, Demirtürk N, Çetinkaya RA et al (2021) Evaluation of the effectiveness and safety of adding ivermectin to treatment in severe COVID-19 patients. BMC Infect Dis 21(1):1-11. https:// doi.org/10.1186/s12879-021-06104-9

84. Shahbaznejad L, Davoudi M, Eslami G et al (2021) Effects of ivermectin in patients with COVID-19: a multicenter, double-blind, randomized, controlled clinical trial. Clin Ther. https://doi.org/10. 1016/j.clinthera.2021.04.007

85. Yang C, Liu E, Liu M (2020) Safety concerns regarding concomitant use of tocilizumab and glucocorticoids in COVID-19 patients. Proc Natl Acad Sci 117(48):30025-30026. https://doi. org/10.1073/pnas.2009253117

86. Zhang S, Li L, Shen A et al (2020) Rational use of tocilizumab in the treatment of novel coronavirus pneumonia. Clin Drug Investig 40(6):511-518. https://doi.org/10.1007/s40261-020-00917-3

87. Ali A, Kamjani MH, Kesselman MM (2020) The role of tocilizumab in cytokine storm and improving outcomes in COVID-19. Recent Pat Anti-Infect Drug Discovery 15(2):104-112. https:// doi.org/10.2174/1574891X15666200922155712

88. Saha A, Sharma AR, Bhattacharya M et al (2020) Tocilizumab: a therapeutic option for the treatment of cytokine storm syndrome in COVID-19. Arch Med Res 51(6):595-597. https://doi.org/10. 1016/j.arcmed.2020.05.009

89. Bhandari S, Rankawat G, Singh G (2021) Tocilizumab: an effective therapy for severely and critically ill COVID-19 patients.
Indian Journal of Critical Care Medicine: Peer-reviewed, Official Publication of Indian Society of Critical Care Medicine 25(3):260-266. https://doi.org/10.5005/jp-journals-10071-23747

90. Zhang C, Wu Z, Li JW et al (2020) The cytokine release syndrome (CRS) of severe COVID-19 and interleukin-6 receptor (IL-6R) antagonist tocilizumab may be the key to reduce mortality. Int J Antimicrob Agents. https://doi.org/10.1016/j.ijantimicag.2020. 105954

91. RECOVERY Collaborative Group (2021) Tocilizumab in patients admitted to hospital with COVID-19 (RECOVERY): a randomised, controlled, open-label, platform trial. Lancet 397(10285):1637-1645. https://doi.org/10.1016/S0140-6736(21) 00676-0

92. RECOVERY Collaborative Group (2021) Azithromycin in patients admitted to hospital with COVID-19 (RECOVERY): a randomised, controlled, open-label, platform trial. The Lancet 397(10274):605-612. https://doi.org/10.1016/S0140-6736(21) 00149-5

93. E Wilkinson 2020 RECOVERY trial: the UK covid-19 study resetting expectations for clinical trials BMJ 369 https://doi.org/10. 1136/bmj.m1626

94. WHO Solidarity Trial Consortium, Pan H, Peto R, HenaoRestrepo AM et al (2021) Repurposed antiviral drugs for COVID-19-interim WHO solidarity trial results. N Engl J Med 384(6):497-511. https://doi.org/10.1056/NEJMoa2023184

95. Ader F, Bouscambert-Duchamp M, Hites M et al (2021) Remdesivir plus standard of care versus standard of care alone for the treatment of patients admitted to hospital with COVID-19 (DisCoVeRy): a phase 3, randomised, controlled, open-label trial. Lancet Infect Dis. https://doi.org/10.1016/S1473-3099(21)00485-0

Publisher's Note Springer Nature remains neutral with regard to jurisdictional claims in published maps and institutional affiliations. 